\title{
Effect of Gamification on Motivated Learning Strategies among College Students
}

\author{
Mohd. Moshahid ${ }^{1}$ and Abdunnzar, P.T. ${ }^{2}$
}

\begin{abstract}
${ }^{1}$ Professor, Mulana Azad National Urdu University, Hyderabad, India
${ }^{2}$ Research Scholar, Mulana Azad National Urdu University, Hyderabad, India

Corresponding author: nasarvalapuram@gmail.com
\end{abstract}

\begin{abstract}
Gamification is becoming highly popular in the scenario of teaching and learning activities. It is a powerful educational strategy for academic process as it instigates and enhances the motivation for the learners of digital generation. The study was carried out using a correlational descriptive design. The population of the study college students of Malappuram district, Kerala. The sample selected for the study comprised of 153 students which is selected using random sampling technique. The points, badges and leader boards were given to students as gamified strategies for online classes using LMS with a maximum score of 30. Motivated Strategies for Learning Questionnaire (MSLQ) is used to assess students' motivation towards learning. The statistical tests used for analysis of data are, person's correlation test and simple liner regression analysis. The study found that there is a significant effect of gamification on motivation among college students as overall and in a varying degree in its various dimensions. The study concluded that there is a significant effect and gamification is moderate predictor of motivation for learning among college students.
\end{abstract}

Keywords: Game, Game Dynamics Gamification, Motivation and Motivated Learning Strategies

The concept of gamification has been popularly in discussion in the scenario of education (McGonigal, 2011). The term may be coined by Nick Pelling (Deterding, Dixon, Khaled \& Nacke, 2011). Games are inextricable from the human culture as deeply rooted in the human psych since the origin of human being (Bunchball, 2010). The central tenet of gaming is the reward system that motivates the participants to achieve certain goals with spirited mind 
(Glover, 2013). Motivational elements are highly important in gamified learning that may boost students' academic engagement and sustain the interest in learning. Gamification is a powerful tool in educational practices especially in the domains of individual learning, group learning, collaborative learning etc. with its effective incentive system. Games are thought to be powerful tool for academic activities for students of current generation (Kapp, 2015). The principle of joyfulness in games mostly helps instigate the learners to engage with teaching and learning tasks that may improve retention.

Teachers are expected to address the issues of motivation and interest in students by sufficiently supplementing advanced digital technologies with proper reward and incentives in instructional practices. Creating a gameful environment is pivotal issue that highlights the rules to frame to immerse players in fun and other joyful activities (Annansingh, 2017). The students of 'digital natives' rightly demand advanced teaching strategies that would be motivated with modern technology boosting their expectations to be engaged beyond conventional teaching methodologies (Lister 2015).

Gamification is the incorporation of game design elements into non-game contexts (Nicholson, 2012). Gamification is the implementation of the game mechanics to non game activities to change people's behaviour (Bunchball, 2010). According to Salen \& Zimmerman (2003) gamification is 'a system in which participants engage in artificial conflict, defined by rules that result in a quantifiable outcome'.

\section{Components of Gamification}

Gamification is functioning to merge academic activities using some game techniques such as scores, points, leaderboards, badges, rewards and badges for achieving goals of various levels of learning tasks (Poondej \& Lerdpornkulrat 2016). Rewardig system is central in gamification process which may be in the form of awards, leaderboads, badges, and points that work as external motivators to learners in gamified learning environment (Goehle, 2013). Hence, it is working in terms of game elements, mechanics, aesthetics, and game thinking in non-game environment (Cunningham \& Zichermann, 2011).

\section{Gamification and Education}

Numerous studies have been carried out to analyse the effectiveness of gamification in relation to teaching and learning activities in a broad variety of disciplines (Cronk 2012; Goehle, 2013; Lambert \& Ennis 2014; Tsay, Kofinas, \& Luo, 2018; Denny, McDonald, Empson, Kelly, \& Petersen, 2018). The increasing popularity and attraction of gamified teaching strategies in educational scenario take away the old and conventional methods of teaching on account of its ineffectiveness for the students from yonger generation. Gamification is paramount in meeting the academic needs of the learners from 'digital natives' or ' $Z$ ' generation as which necessitates addressing certain critical challenge to teachers to implement newest and innovative teaching 
and learning instructional methods and strategies. Gamification has been rightly made some credentials in the scenario of teaching and learning activities facilitating learning environment with technology mediated communication. Hence gamification techniques can be effectively applied to augment the teaching and learning engagements. It is also helpful for bringing behavioural changes in students by enhancing involvement in academic activities (Decker \& Lawley, 2013). Gamification is thought to be an important teaching and learning technique that can highly enhance retention power among students with immersive engagement in academic activities.

\section{Rationale for the Study}

Gamification activates intrinsic and extrinsic motivation among students towards their learning. Incorporation of gaming mechanics and game elements to teaching and learning activities can rightly enhance student's engagement in teaching and learning activities. Gamification can be considered as innovative strategy for not only pedagogic practices but also and ragogic practices especially it is highly potential to meet the instructional needs of learners from web based learning generation. Hence the studying the impact of gamification on motivation of students is very important since it should be studied the effect of gamified strategies on various aspects of motivation for learning like intrinsic goal orientation, extrinsic goal orientation, monitoring learning beliefs, self-efficacy and learning performance, autonomy of learners and level of engagement etc. which can greatly impact the academic development of students.

\section{Review of Related Studies}

Imran (2019) found that students spend more time in gamified learning environment for academic activities than in non-gamified learning environments. Ding, Erkan, \& Orey (2018) reported enhanced learning activities of students in dimensions of cognitive, behavioural, and emotional engagement. It is also found a positive effect of gamification on academic engagement of students. Bouchrika, Harrati, Wanick \& Wills (2019) found gamification as significant technique to motivate the learners in educational systems that help enhance interactivity of learners and academic engagement as well. Huang, Hew \& Lo (2019) reported that gamification has a significant and positive effect on academic engagement of students in performing learning activities and enhancing student's academic outcomes. Kyewski \& Kramer (2018) showed that the badges ad game element have no significant impact on motivation for learning performance of students. Chapman \& Rich (2018) found no significant relation between overall motivation and the gamified learning. It also found that gender, age, hours spend, student status are not significant predictors of motivation for gamifications.

Khan, Ahmad \& Malik (2017) found that the game based academic activities have a significant effect on students' learning engagement. It also reported that gamified learning strategies were not equally effective for all learners. Buckley \& Doyle (2016) found significant development 
in knowledge and awareness of learners by implementing the gamified learning intervention. Maria -Blanca, Di-Serio \& Delgado-Kloos (2014) found positive effect of gamification on the learning engagement among students in learning activities and a sufficient enhancement of learning outcomes. Goehle (2013) found that students are more interested and felt more fun in learning with the gamified strategies. Barata et al, (2013) found that students are interested in spending more time for learning activities as the motivation from obtaining badges, points, leaderboard, and attaining positive reactions from peer learners.

\section{Objectives of the Study}

1. To find out the effect of gamification on motivated learning strategies among college students.

2. To find out the effect of gamification on intrinsic goal orientation among college students.

3. To find out the effect of gamification on extrinsic goal orientation among college students.

4. To find out the effect of gamification on task value among college students.

5. To find out the effect of gamification on value components among college students.

6. To find out the effect of gamification on control of learning beliefs among college students.

7. To find out the effect of gamification on self-efficacy for learning and performance among college students.

8. To find out the effect of gamification on expectancy component among college students.

9. To find out the effect of gamification on test anxiety among college students.

\section{Hypothesis of the Study}

1. There will be significant effect of gamification on motivation among college students.

2. There will be significant effect of gamification on intrinsic goal orientation among college students.

3. There will be significant effect of gamification on extrinsic goal orientation among college students.

4. There will be significant effect of gamification on task value among college students.

5. There will be significant effect of gamification on value components among college students.

6. There will be significant effect of gamification on control of learning beliefs among college students.

7. There will be significant effect of gamification on self-efficacy for learning and performance among college students. 
8. There will be significant effect of gamification on expectancy component among college students.

9. There will be significant effect of gamification on test anxiety among college students.

\section{Methodology}

A correlational descriptive design is used to conduct the study. The population of the study is all undergraduate college students studying in Malappuarm. The sample selected for the study comprised of 128 students that have been selected through random sampling technique. Independent variable is gamification and depended variable is motivated learning strategies for learning. The student was given gamified online classes using LMS with three gamified strategies i.e. points, badges and leaderboards with a maximum score 30. Students' motivated strategies for learning are assessed using Motivated Strategies for Learning Questionnaire (MSLQ). Value components, expectancy components, and affective component are taken for assessment of motivated strategies for learning. Intrinsic goal orientation, extrinsic goal orientation and task value are components involved in value components. Control of learning beliefs and self-efficacy for learning and performance are the components involved in expectancy components. Test anxiety is assessed by the affective component. MSLQ is seven point scale having 31 items that are taken from these three dimensions. The reliability coefficient of the tool is .95 and it has higher level construct validity as well. The statistical tests used for analysis of data are, person's correlation and simple liner regression analysis.

\section{Analysis and Interpretation}

Table 1: Regression Coefficients of Gamification on Motivated Learning Strategies as whole among college students

\begin{tabular}{cccc}
\hline Variable & $\boldsymbol{B}$ & $\boldsymbol{\beta}$ & $\boldsymbol{S E}$ \\
\hline Constant & $9.89^{* * *}$ & & .85 \\
Gamification & $.09 * * *$ & .71 & .01 \\
\hline $\mathrm{R}^{2}$ & .49 & & \\
\hline
\end{tabular}

Note: $N=153 ; * * * p<.001$.

Table 1 shows the effect of gamification on motivated learning strategies among college students. The $R^{2}$ value of .49 revealed that the predictor variable explained $49 \%$ variance in the outcome variable with $F(1,152)=150.48, p<.001$. The finding revealed that gamification positively predicted motivated learning strategies $(\beta=.71, p<.001)$. There is significant effect of gamification on motivated learning strategies among college students. Hence, the null hypothesis is rejected and the alternative hypothesis is accepted. 
Table 2: Regression Coefficients of Gamification on Intrinsic Goal Orientation among college students

\begin{tabular}{cccc}
\hline Variable & $\boldsymbol{B}$ & $\boldsymbol{\beta}$ & $\boldsymbol{S E}$ \\
\hline Constant & $13.75^{* * *}$ & & .82 \\
Gamification & $.39 * * *$ & .55 & .05 \\
\hline $\mathrm{R}^{2}$ & .30 & & \\
\hline
\end{tabular}

Note: $N=153 ; * * * p<.001$.

Table 2 shows the effect of gamification on intrinsic goal orientation among college students. The $R^{2}$ value of .30 revealed that the predictor variable explained $30 \%$ variance in the outcome variable with $F(1,152)=63.4, p<.001$. The finding revealed that gamification positively predicted intrinsic goal orientation $(\beta=.55, p<.001)$. There is significant effect of gamification on intrinsic goal orientation among college students. Hence, the null hypothesis is rejected and the alternative hypothesis is accepted.

Table 3: Regression Coefficients of Gamification on Extrinsic Goal Orientation among College Students

\begin{tabular}{cccc}
\hline Variable & $\boldsymbol{B}$ & $\boldsymbol{\beta}$ & $\boldsymbol{S E}$ \\
\hline Constant & $10.23^{* * *}$ & & .98 \\
Gamification & $.46^{* * *}$ & .64 & .06 \\
\hline $\mathrm{R}^{2}$ & .41 & & \\
\hline
\end{tabular}

Note: $N=153 ; * * * p<.001$.

Table 3 shows the effect of gamification on extrinsic goal orientation among college students. The $R^{2}$ value of .41 revealed that the predictor variable explained $41 \%$ variance in the outcome variable with $F(1,152)=103.60, p<.001$. The finding revealed that gamification positively predicted extrinsic goal orientation $(\beta=.64, p<.001)$. There is significant effect of gamification on extrinsic goal orientation among college students. Hence, the null hypothesis is rejected and the alternative hypothesis is accepted.

Table 4: Regression Coefficients of Gamification on Task Value among College Students

\begin{tabular}{cccc}
\hline Variable & $\boldsymbol{B}$ & $\boldsymbol{\beta}$ & $\boldsymbol{S E}$ \\
\hline Constant & $12.49^{* * *}$ & & .749 \\
Gamification & $.33^{* * *}$ & .65 & .032 \\
\hline $\mathrm{R}^{2}$ & .42 & & \\
\hline
\end{tabular}

Note: $N=153 ; * * * p<.001$.

Table 4 shows the effect of gamification on task value among college students. The $R^{2}$ value of .42 revealed that the predictor variable explained $42 \%$ variance in the outcome variable with $F(1,152)=109.33, p<.001$. The finding revealed that gamification positively predicted task 
value $(\beta=.65, p<.001)$. There is significant effect of gamification on task value among college students. Hence, the null hypothesis is rejected and the alternative hypothesis is accepted.

Table 5: Regression Coefficients of Gamification on Value Components among College Students

\begin{tabular}{cccc}
\hline Variable & $\boldsymbol{B}$ & $\boldsymbol{\beta}$ & $\boldsymbol{S E}$ \\
\hline Constant & $10.4^{* * *}$ & & .85 \\
Gamification & $.16^{* * *}$ & .66 & .01 \\
\hline $\mathrm{R}^{2}$ & .47 & & \\
\hline
\end{tabular}

Note: $N=153 ; * * * p<.001$.

Table 5 shows the effect of gamification on value components among college students. The $R^{2}$ value of .47 revealed that the predictor variable explained $47 \%$ variance in the outcome variable with $F(1,152)=133.73, p<.001$. The finding revealed that gamification positively predicted the value components $(\beta=.66, p<.001)$. There is significant effect of gamification on value components among college students. Hence, the null hypothesis is rejected and the alternative hypothesis is accepted.

Table 6: Regression Coefficients of Gamification on Control Beliefs among College Students

\begin{tabular}{cccc}
\hline Variable & $\boldsymbol{B}$ & $\boldsymbol{\beta}$ & $\boldsymbol{S E}$ \\
\hline Constant & $14.31^{* * *}$ & & .69 \\
Gamification & $.46^{* * *}$ & .59 & .05 \\
\hline $\mathrm{R}^{2}$ & .34 & & \\
\hline
\end{tabular}

Note: $N=153 ; * * * p<.001$.

Table 6 shows the effect of gamification on control beliefs among college students. The $R^{2}$ value of .34 revealed that the predictor variable explained $6 \%$ variance in the outcome variable with $F(1,152=77.76, p<.001$. The finding revealed that gamification positively predicted the control beliefs $(\beta=.59, p<.001)$. There is significant effect of gamification on control beliefs among college students. Hence, the null hypothesis is rejected and the alternative hypothesis is accepted.

Table 7: Regression Coefficients of Gamification on Self-Efficacy for Learning and Performance among College Students

\begin{tabular}{cccc}
\hline Variable & $\boldsymbol{B}$ & $\boldsymbol{\beta}$ & $\boldsymbol{S E}$ \\
\hline Constant & $11.42 * * *$ & & .82 \\
Gamification & $.29 * * *$ & .66 & .03 \\
\hline $\mathrm{R}^{2}$ & .44 & & \\
\hline
\end{tabular}

Note: $N=153 ; * * * p<.001$. 
Table 7 shows the effect of gamification on self-efficacy for learning and performance among college students. The $R^{2}$ value of .44 revealed that the predictor variable explained $44 \%$ variance in the outcome variable with $F(1,152)=116.44, p<.001$. The finding revealed that gamification positively predicted the self-efficacy for learning and performance $(\beta=.66, p<.001)$. There is significant effect of gamification on self-efficacy for learning and performance among college students. Hence, the null hypothesis is rejected and the alternative hypothesis is accepted.

Table 8: Regression Coefficients of Gamification on Expectancy Components among College Students

\begin{tabular}{cccc}
\hline Variable & $\boldsymbol{B}$ & $\boldsymbol{\beta}$ & $\boldsymbol{S E}$ \\
\hline Constant & $11.45^{* * *}$ & & .78 \\
Gamification & $.21^{* * *}$ & .68 & .02 \\
\hline $\mathrm{R}^{2}$ & .46 & & \\
\hline
\end{tabular}

Note: $N=153 ; * * * p<.001$.

Table 8 shows the effect of gamification on expectancy components among college students. The $R^{2}$ value of .46 revealed that the predictor variable explained $46 \%$ variance in the outcome variable with $F(1,152)=128.42, p<.001$. The finding revealed that gamification positively predicted the expectancy components $(\beta=.68, p<.001)$. There is significant effect of gamification on expectancy components among college students. Hence, the null hypothesis is rejected and the alternative hypothesis is accepted.

Table 9: Regression Coefficients of Gamification on Test Anxiety among College Students

\begin{tabular}{cccc}
\hline Variable & $\boldsymbol{B}$ & $\boldsymbol{\beta}$ & $\boldsymbol{S E}$ \\
\hline Constant & $13.07^{* * *}$ & & .94 \\
Gamification & $.38^{* * *}$ & .52 & .05 \\
\hline $\mathrm{R}^{2}$ & .27 & & \\
\hline
\end{tabular}

Note: $N=153 ; * * * p<.001$.

Table 9 shows the effect of gamification on test anxiety among college students. The $R^{2}$ value of .27 revealed that the predictor variable explained $27 \%$ variance in the outcome variable with $F(1,152)=56.83, p<.001$. The finding revealed that gamification positively predicted the test anxiety $(\beta=.52, p<.001)$. There is significant effect of gamification on test anxiety among college students. Hence, the null hypothesis is rejected and the alternative hypothesis is accepted.

\section{DISCUSSION}

The study reported a significant effect of gamification on motivation among college students. It is found that there are various degrees in effect of gamification on different dimensions of motivation towards learning among college students. The Study found a significant effect of gamification on motivated learning strategies and gamification is a moderate predictor on 
motivated learning among college students. The prediction of gamification on motivation as whole, value components, expectation components and affective components are $49 \%$, 47\%, $46 \%$ and $27 \%$ respectively that show varied range of prediction of gamification on various components of motivated learning strategies. The findings of the study are supported by Gasland, 2011; Cronk, 2012; McDaniel et al. 2012; Denny, 2013; de- Marcos et al. 2014; SanchezMartin \& Davila-Acedo, 2017; Lo \& Hew, 2018; Huang \& Hew, 2018; Imran, 2019). The findings of the study is not supported with Cramer, Rost, \& Holmquist, 2011; Hanus \& Fox, 2015; Kyewski \& Kramer, 2018).

\section{CONCLUSION}

Motivation is substantial in teaching and learning activities. Emotional and behavioral engagement of learners in academic activities can be maximised only by sufficient intrinsic and extrinsic motivation. This study explored the effect of gamification on motivated learning among college students. The study mainly focused on to measure various motivated learning strategies such as intrinsic and extrinsic goal orientation, task value, and control on learning beliefs, self-efficacy for learning performance and anxiety related to test of learners on gamification. Results suggest points, badges and leaderboards are important measures for motivation for learning experiences among college students. The results showed a moderate positive effect of gamification on motivation among college students. This study contributes to the understanding of how gamification impacts the motivation of students on their academic engagement. The study recommends incorporating more diversified game elements in teaching and learning activities that can highly enhance motivation in students for accelerated learning.

\section{REFERENCES}

1. Annansingh, F. 2017. An investigation into the gamification of e-learning in higher education. In: Alphin Jr, H.C., Lavine, J. \& Chan, R.Y (Eds.). Disability and Equity in Higher Education Accessibility. City University of New York - York College, USA.

2. Barata, G., Gama, S., Jorge, J. and Gonçalves, D. 2013. Improving participation and learning with gamification. In Proceedings of the First International Conference on gameful design, research, and applications 10-17.ACM.

3. Bouchrika, I., Harrati, N., Wanick, V. and Wills, G. 2019. Exploring the impact of gamification on student engagement and involvement with e-learning systems, Interactive Learning Environments, DOI: 10.1080/10494820.2019.1623267.

4. Buckley, P. and Doyle. 2016. Gamification and student motivation, Interactive Learning Environments, 24(6): 1162-1175.

5. Bunchball. 2010. Gamification : An Introduction to the Use of Game Dynamics to Influence Behaviour. Retrieved from: www.bunchball.com.

6. Chapman, J.R. and Rich, P.J. 2018. Does educational gamification improves students' motivation? If so, which game elements work best? Journal of Education form Business, 93(7): 315-322. 
7. Cramer, H., Rost, M. and Holmquist, L.E. 2011. Performing a check in: emerging practices, norms and "conflicts" in location sharing using four square. In: Proceedings of the $13^{\text {th }}$ International Conference on Human-Computer Interaction with Mobile Devices and Services. ACM, pp. 57-66.

8. Cronk, M. 2012. Using Gamification to increase student engagement and participation in class discussion. In Proceedings of World Conference on Educational Multimedia, Hypermedia and Telecommunications 2012, Denver, Colorado, USA.http://www.editlib.org/p/40762.

9. Cunningham, C. and Zichermann, G. 2011. Gamification by Design: Implementing Game Mechanics in Web and Mobile Apps. O’Reilly Media, Sebastopol, CA.

10. Denny, P., McDonald, F., Empson, R., Kelly, P. and Petersen, A. 2018. Empirical support for a causal relationship between gamification and learning outcomes. In Proceedings of the 2018 CHI Conference on Human Factors in Computing Systems, Montreal QC, Canada.

11. Deterding, S., Dixon, D., Khaled, R. and Nacke, L. 2011. From game design elements togamefulness. Defining gamification. In Proceedings of the 15th International Academic Mind Trek Conference: Envisioning Future Media Environments. ACM, Tampere, Finland, pp. 9-15.

12. Ding, L., Erkan, E. and Orey, M. 2018. An exploratory study of student engagement in gamified online discussions. Computers \& Education, 120: 213-226.

13. Gasland, M.M. 2011. Game Mechanic based E-Learning: A case study. Retrieved from: http://ntnu. diva-portal. org/smash/get/diva2:441760/FULLTEXT01

14. Glover, I. 2013. Play as you learn: Gamification as a technique for motivating learners. In: Herrington, J., Couros, A. \& Irvine, V. (Eds.) Proceedings of World Conference on Educational Multimedia, Hypermedia and Telecommunications 1999-2008. Chesapeake,VA: AACE.

15. Goehle, G. 2013. Gamification and Web-based Homework. Primus: Problems, Resources, and Issues in Mathematics Undergraduate Studies, 23: 234-246.

16. Hanus, M. and Fox, J. 2015. Assessing the effects of gamification in the classroom: A longitudinal study on intrinsic motivation, social comparison, satisfaction, effort, and academic performance. Computers \& Education, 80: 152 - 161.

17. Huang, B., Hew, K.F. and Lo, C.K. 2019. Investigating the effects of gamification enhanced flipped learning on undergraduate students' behavioural and cognitive engagement, Interactive Learning Environments, 27(8): 11061126.

18. Huang, B. and Hew, K.F. 2018. Implementing a theory driven gamification model in higher education flipped courses: Effects on out-of-class activity completion and quality of artefacts. Computers \& Education, 125: 254-272.

19. Imran, H. 2019. Evaluation of awarding badges on Student's engagement in Gamified e-learning systems. Smart Learn. Environment, 6(17).

20. Kapp, K.M. 2012. The gamification of learning and instruction: Game-based methods and strategies for training and education. Pfeiffer; SanFrancisco, CA.

21. Khan, A., Ahmad, F.H. and Malik, M.M. 2017. Use of digital game based learning and gamification in secondary school science: The effect on student engagement, learning and gender difference. Educational Information Technology, 22(6): 2767-2804.

22. Kyewski, E. and Krämer, N.C. 2018. To gamify or not to gamify? An experimental field study of the influence of badges on motivation, activity, and performance in an online learning course. Computer Education, 118: 25-37. 
23. Lambert, J. and Ennis, J. 2014. Quest-based learning: A new approach to pre service teacher technology instruction. In Proceedings of Information Technology \& Teacher Education International Conference.

24. Lister, M.C. 2015. Gamification: The effect on student motivation and performance at the postsecondary level. Issues and Trends in Educational Technology, 3(2).

25. Lo, C.K. and Hew, K.F. 2018. A comparison of flipped learning with gamification, traditional learning, and online independent study: The effects on students' mathematics achievement and cognitive engagement. Interactive Learning Environments, pp. 1-18.

26. Mariia-Blanca I., Di-Serio, A. and Delgado-Kloos, C. 2014. Gamification for engaging computer science students in learning activities: A case study. IEEE Transactions on Learning Technologies, 7(3): 291-300.

27. McGonigal, J. 2011. Reality is broken: Why games make us better and how they can Change the world. London: UK: Jonathan Cape.

28. Nicholson, S. 2012. A user-cantered theoretical framework for meaningful gamification. In Proceedings of Games Learning Society, 8.0. Madison,WI.

29. Palomino, P.T., Armando, T.M., Wilk, O., Alexandra, C. and Seiji, I. 2019. Narrative for gamification in education: Why should you Care? In Proceedings of IEEE $19^{\text {th }}$ International conference on advanced learning technologies .10.1109/ICALT.2019.00035.

30. Poondej, C. and Lerdpornkulrat, T. 2016. The development of gamified learning activities to increase student engagement in learning. Australian Educational Computing, 31(2).

31. Salen, K. and Zimmerman, E. 2003. Rules of Play: Game Design Fundamentals. The MIT Press. Cambridge, MA, pp. 80 .

32. Sanchez-Martin, J. and Davila-Acedo, M.A. 2017. Just a game? Gamifying a general science class at university: Collaborative and competitive work implications. Thinking Skills and Creativity, 26: 51-59.

33. Tsay, C., Kofinas, A.K. and Luo, J. 2018. Enhancing student learning experience with technology-mediated gamification: an empirical study, Computers and Education, 121: 1-17. 